DOI https://doi.org/10.15589/znp2021.4(487).5

УДК 629.5.04: 629.5.048

\title{
DECENTRALIZED MULTIPARAMETRIC CONTROL OF INDOOR AIR QUALITY AND COMFORT ON BOARD SHIPS: A PRACTICAL APPROACH
}

\section{ДЕЦЕНТРАЛІЗОВАНЕ БАГАТОПАРАМЕТРИЧНЕ УПРАВЛІННЯ ЯКІСТЮ ТА КОМФОРТНІСТЮ ПОВІТРЯ СУДНОВИХ ПРИМІЩЕНЬ: ПРАКТИЧНИЙ ПІДХІД}

\author{
Viktor A. Bily \\ bily.viktor@gmail.com \\ ORCID: 0000-0001-6354-0790
}

\author{
В. А. Білий, \\ аспірант
}

\author{
National University “Odessa Maritime Academy”, Odessa \\ Національний університет «Одеська морська академія», м. Одеса
}

\begin{abstract}
Purpose. Maintaining the indoor air quality of ship's premises can be done by cleaning it and managing its distribution. The advantages of air distribution control systems are low cost and the installation feasibility in the air conditioning system of existing vessels. The use of air distribution control devices allows to protect the air of living and working spaces from aerosols, particulate matter and pollutants. The creation of effective automatic systems for the distribution of indoor air superstructure requires the determination of static and dynamic characteristics of both typical units (fan, air cooler, filter, air ducts) and the system as a whole. The purpose of this research is to develop a prototype of the automatic air quality and comfort management system, study of its dynamic characteristics and approbation during the voyage of a gas carrier vessel.

Method. Methods of system analysis, comparison, synthesis were used for the research. The object of the study is indoor air quality and comfort management system, its impact on the processes of air distribution in the superstructure and the spread of pollutants. The subject of the study is the effectiveness of maintaining the safety and comfort of the indoor air on board ships.

Results. A decentralized automatic air quality and comfort management system has been developed. The system was tested on board the gas carrier vessel during laden and ballast voyages, cargo operations and gas freeing. The dynamic characteristics of living premises as an object of air quality and comfort management are studied.

Scientific novelty. The developed system of automatic control allows to maintain indicators of onboard premises indoor air in safe and comfortable limits. The principle of the system design allows its scaling and extension by including of additional components, such as filters, absorbers, etc.

Practical significance. The study of the proposed system effectiveness allows us to recommend it for inclusion in the projects of new vessels and installation in existing air conditioning systems. The structure of the system is modular, which determines its reliability and minimum maintenance requirements during operation.

Key words: microclimate; air distribution; automatic control system; decentralized system; indoor air quality.
\end{abstract}

Анотація. Мета. Підтримання якості внутрішнього повітря суднових приміщень може здійснюватися через його очищення та керування розподілом. Перевагами систем керування розподілом повітря є їх невелика вартість та можливість установлення в повітропроводах системи кондиціювання наявних суден. Використання приладів керування розподілом повітря дозволяє забезпечити захист повітря житлових та робочих приміщень від аерозолів, твердих частинок дрібних фракцій та забруднювальних газів. Створення ефективних автоматичних систем управління якістю та комфортністю надбудови потребує визначення статичних та динамічних характеристик як типових ланок (вентилятора, повітроохолоджувача, фільтра, повітропроводів), так і системи загалом. Метою цього дослідження є розробка прототипу системи автоматичного управління якістю та комфортністю повітря, дослідження його динамічних характеристик та апробація за умов використання протягом рейсу судна-газовоза.

Методика. Під час дослідження застосовувались методи системного аналізу, порівняння, синтезу. Об'єктом дослідження є система управління якістю та комфортністю повітря приміщень та ії вплив на процеси розподілу повітря в надбудові судна й розповсюдження забруднювачів. Предметом - ефективність підтримання безпечності та комфортності газового складу повітря в суднових приміщеннях. 
Результати. Розроблено децентралізовану систему автоматичного управління якістю та комфортністю повітря. Апробовано систему на борту судна-газовоза під час різних режимів його роботи (навантаженого та баластного рейсу, вантажних операцій та дегазації). Досліджено динамічні характеристики повітря житлового приміщення як об'єкта керування якістю повітря.

Наукова новизна. Розроблена система автоматичного управління дозволяє підтримувати показники повітря приміщень судна в безпечних та комфортних межах. Принцип побудови та структура системи уможливлюють iii масштабування та включення до іiі складу додаткових компонентів, як-от фільтри, абсорбери та ін.

Практична значимість. Дослідження ефективності запропонованої системи автоматичного управління якістю та комфортністю повітря дозволяє рекомендувати іiі для включення в проєкти нових суден та встановлення в системах кондиціювання наявних. Структура системи є модульною, що зумовлює їі надійність та мінімальні вимоги до технічного обслуговування під час експлуатації.

Ключові слова: мікроклімат; розподіл повітря; система автоматичного управління; децентралізована система.

\section{ПОСТАНОВКА ЗАВДАННЯ}

Потреба в гарантуванні безпечного газового складу повітря надбудови актуальна не тільки для суден, які перевозять небезпечні вантажі (танкери, хімовози та газовози), а й для суден інших типів, оскільки такі джерела забруднення, як вихлопні гази двигунів, котлів, інсинераторів, випаровування палива, мастила, $є$ спільними для них.

Під час проєктування суднових систем очищення повітря важливо враховувати нестабільність концентрації забруднювачів у зовнішньому та внутрішньому повітрі через зміни курсу та швидкості судна, напрямку вітру, режимів роботи суднового обладнання. Забезпечити належну якість та комфортність внутрішнього повітря суднових приміщень здатні лише системи автоматичного керування очищенням та розподілом повітря за умови точного врахування динамічних характеристик об'єктів керування.

\section{АНАЛІЗ ОСТАННІХ ДОСЛІДЖЕНЬ І ПУБЛІКАЦІЙ}

Автори роботи [1] підсумовують результати досліджень принципів енергоефективного управління комфортністю повітря приміщень та відповідних оптимізаційних алгоритмів. Більшість досліджених систем управління побудовані на принципах прогностичного контролю, баготоагентного управління, нечіткої логіки та релейного керування. Найбільш використовуваними методами оптимізації є такі: генетичні, багатопараметричної оптимізації рою частинок, оптимізації розкладу та багатопарамеричні генетичні алгоритми.

У роботі [2] вирішується завдання децентралізованого управління температурою повітря групи суміжних приміщень за умов одночасної мінімізації енергетичних витрат системи кондиціювання повітря. Вирішення оптимізаційного завдання проводиться з використанням моделі опору -ємності для моделювання теплообміну та субградієнтного методу опуклої оптимізації. Децентралізований підхід дозволяє значно знизити вимоги до обчислювальної складності алгоритмів керування, що спрощує реалізацію системи з використанням сучасних контролерів реального часу, які виконують функції незалежних інтелектуальних агентів, пов'язаних із центральним контролером. Запропонований підхід є перспективним для забезпечення оптимального багатопараметричного керування комфортністю та якістю повітря за умови використання адекватної математичної моделі тепломасообмінних процесів.

Автори дослідження [3] запропонували дворівневий метод децентралізованого управління комфортністю температури та якістю повітря декількох суміжних зон. Критерієм якості повітря використана концентрація $\mathrm{CO}_{2}$. Алгоритм верхнього рівня методу призначений для розрахунку масової витрати припливного повітря в кожній контрольованій зоні для підтримання комфортної температури з мінімальними витратами енергії системи кондиціювання. Алгоритм нижнього рівня методу використовується для визначення масової витрати припливного повітря для підтримання встановленого рівня якості повітря. Математичне моделювання показало перспективність використання запропонованого підходу для ефективного одночасного керування комфортністю та якістю повітря. Перевагами цього підходу є використання математичної моделі з урахуванням комфортності та якості повітря приміщень. Слід зауважити, що для використання запропонованого підходу в суднових системах вентиляції та кондиціювання його потрібно вдосконалити за допомогою врахування динаміки вмісту водяної пари у внутрішньому повітрі приміщень та вмісту забруднювачів у зовнішньому повітрі.

Згідно 3 міжнародними нормами для визначення якості повітря, крім вмісту $\mathrm{CO}_{2}$, використовують показники вмісту озону, монооксиду вуглецю, твердих частинок та летких органічних речовин. Велика кількість контрольованих параметрів призводить до збільшення обчислювальної складності систем керування. У дослідженні [4] запропоновано використовувати апарат теорії грубих множин, метод зменшення кількості атрибутів та нейронних сіток для зменшення кількості значущих контрольованих параметрів для визначення якості повітря та відповідної обчислювальної складності. 


\section{АВТОМАТИЗАЦІЯ ТА КОМП'ЮТЕРНО-ІНТЕГРОВАНІ ТЕХНОЛОГІЇ № 4 - 2021}

Практичну реалізацію витратоефективної системи моніторингу якості повітря розглянуто в роботі [5]. Автори використовували контролер Arduino Mega128, датчик пилу фірми Sharp та датчик моноксиду вуглецю MQ-7 фірми Hanwei Electronics.

У роботі [6] наведено систематичний аналіз рекомендацій та стандартів якості повітря й огляд технологій витратоефективних датчиків якості повітря, відповідних специфікацій, як-от типовий діапазон та точність вимірювання, повторюваність, роздільна здатність, час відгуку та ринкова ціна. Автори також розглядають дані польових досліджень технічних характеристик зазначених датчиків.

\section{ВИОКРЕМЛЕННЯ НЕ ВИРІШЕНИХ РАНІШЕ ЧАСТИН ЗАГАЛЬНОЇ ПРОБЛЕМИ}

Аналіз останніх публікацій показав, що додаткового дослідження потребують вплив періодичного забруднення зовнішнього повітря змінної інтенсивності на динаміку розповсюдження забруднювачів у приміщеннях надбудови та перспективи використання принципів й алгоритмів управління якістю і комфортністю повітря приміщень у суднових умовах.

\section{МЕТА ДОСЛІДЖЕННЯ}

Метою дослідження $є$ вивчення ефективності застосування децентралізованого багатопараметричного управління якістю та комфортністю повітря 3 використанням прототипу системи автоматичного розподілу повітря, дослідження іiї динамічних характеристик та апробація за умов використання протягом рейсу судна-газовоза.

\section{МЕТОДИ, ОБ'ЄКТ ТА ПРЕДМЕТ ДОСЛІДЖЕННЯ}

У роботі застосовувались методи системного аналізу, порівняння, синтезу. Об'єктом дослідження $\epsilon$ суднова система децентралізованого багатопараметричного управління якістю й комфортністю повітря приміщень та ऑї вплив на процеси теплообміну, розподілу повітря та розповсюдження забруднювального газу в судновій надбудові. Предметом ефективність забезпечення комфортності та безпечності газового складу повітря суднових приміщень.

\section{ОСНОВНИЙ МАТЕРІАЛ}

Аналіз останніх публікацій за темою дослідження показав, що перспективним із точки зору витратоефективності та обчислювальної складності алгоритмів керування $є$ використання гібридних децентралізованих систем.

Для досягнення цілей дослідження спроєктовано та створено експериментальну систему багатопараметричного управління якістю та комфортністю повітря в приміщеннях судна-газовоза за такими критеріями, як уміст вуглеводнів та двоокису вуглецю, загальна якість у $\mathrm{CO}_{2}$-еквівалентних одиницях, температура повітря в приміщенні. Дослідження ефективності системи тривало протягом двох місяців на борту судна-газовоза, яке перевозило пропілен.

Досліджувана децентралізована система управління складається 3: регулятора якості повітря приміщення (Рис. 1), модуля припливного повітря приміщення (Рис. 2), модуля зовнішнього повітря (Рис. 3).

Регулятор якості повітря приміщення (Рис. 1) побудований на базі контролера Arduino Mega та датчиків: умісту вуглеводнів (MQ-6); умісту $\mathrm{CO}_{2}$ (MH-Z19); якості повітря (MQ-135); температури, вологості та тиску (ВМЕ 280). Передання інформації з модуля зовнішнього повітря реалізовано через радіоканал на частоті $433 \mathrm{MHz}$, а зв'язок із модулем припливного повітря - через провідний протокол UART. Контролер регулятора якості повітря реалізує алгоритм гібридного нечіткого адаптивного ПІД-регулятора. Пріоритетність керованих параметрів повітря приміщень визначається за допомогою нечітких правил: I пріоритет - уміст вуглеводнів, II пріоритет - уміст $\mathrm{CO}_{2}$, III пріоритет - загальна якість повітря у $\mathrm{CO}_{2}$ еквівалентних одиницях, IV пріоритет - температура як показник комфортності. Розрахунок величини панівного впливу здійснюється за ПІД-законом керування згідно з попередньо встановленим пріоритетом та на підставі інформації, отриманої від модулів припливного та зовнішнього повітря. Панівним впливом регулятора $є$ кут відкриття заслінки припливного повітря. Регулятор має модуль постійної пам'яті SD Card для реєстрації параметрів повітря приміщення.

Модуль припливного повітря (Рис. 2) побудований на базі контролера Arduino Nano та датчиків: температури, вологості та тиску (ВМЕ 280); положення заслінки (лінійного потенціометру). Зміна кута відкриття вентиляційної заслінки здійснюється сервоприводом під час отримання контролером відповідної команди від регулятора якості повітря.

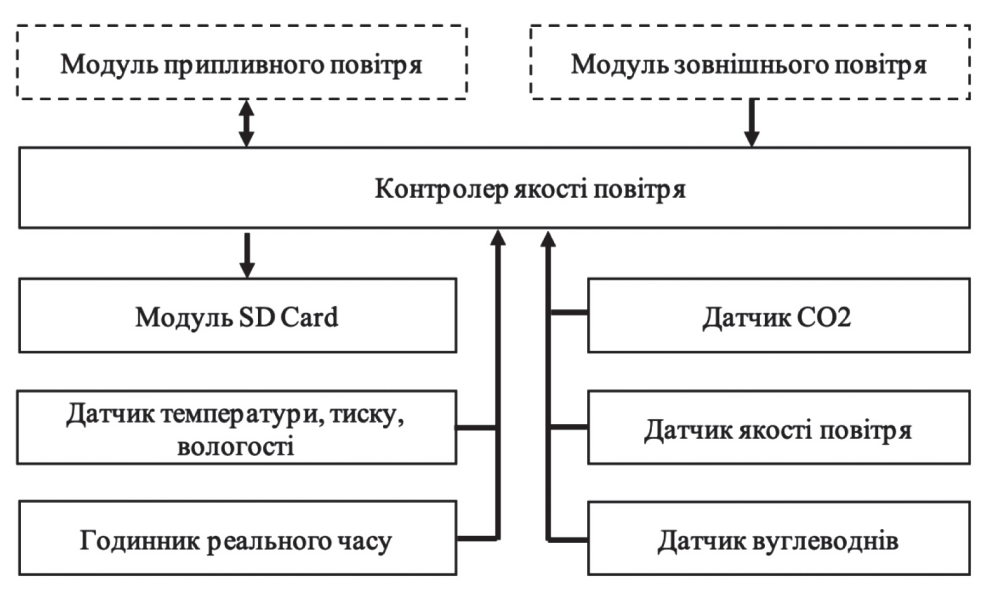

Рис. 1. Схема регулятора якості повітря 
Модуль зовнішнього повітря (Рис. 3) побудований на базі контролера Arduino Nano та датчиків: умісту вуглеводнів (MQ-6); якості повітря (MQ-135); температури, вологості та тиску (ВМЕ 280). Виміряні параметри зовнішнього повітря модуль транслює на частоті $433 \mathrm{MHz}$, що дає змогу масштабувати систему та встановлювати потрібну кількість регуляторів якості повітря в суднових приміщеннях.

Перед початком дослідження проведено калібрування датчиків. Датчики якості повітря MQ-135 калібровані на відкритому повітрі під час якірної стоянки в безвітряну погоду, що дало змогу використовувати як референтне значення вміст діоксиду вуглецю в атмосфері. Калібрування датчиків вуглеводнів MQ-6 здійснювалось із використанням еталонної суміші ізобутану з концентрацією 9000 ppm та сухого

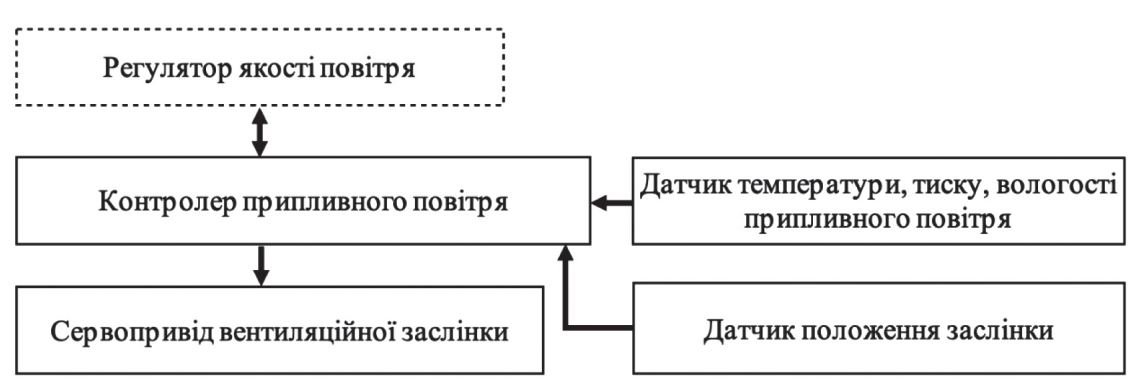

Рис. 2. Схема модуля припливного повітря

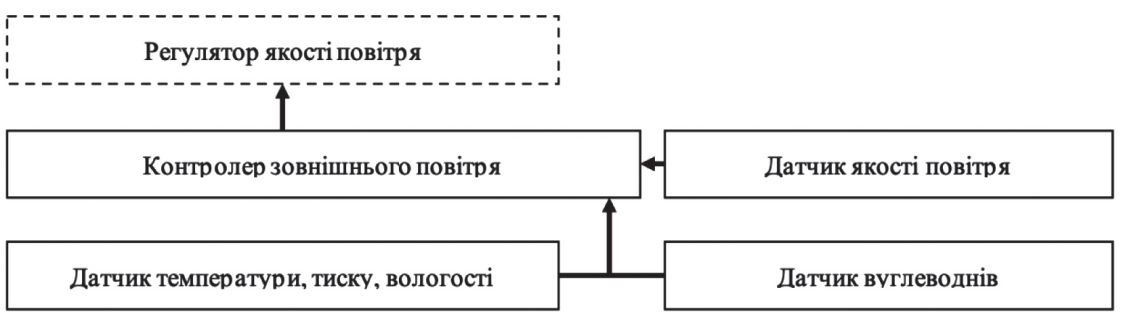

Рис. 3. Схема модуля зовнішнього повітря повітря. Для розрахунку калібрувальних коефіцієнтів обох типів датчиків використовувались калібрувальні криві, надані виробником.

Під час дослідження ефективності системи управління якістю повітря використано такі установки багатопараметричного регулятора якості, як уміст вуглеводнів не вище 200 ppm, уміст вуглекислого газу не вище 1000 ppm, показник якості повітря не вище 1000 ppm $\mathrm{CO}_{2}$, температура повітря $24^{\circ} \mathrm{C}$.

\section{РЕЗУЛЬТАТИ}

Система управління якістю та комфортністю повітря випробувана під час різних режимів роботи судна, але іiі найбільшу ефективність зафіксовано перед початком ремонтних робіт, коли екіпаж проводив дегазацію вантажних танків.

Під час дегазації танків уміст пропілену в зовнішньому повітрі сягав 1370 ppm, що у 2,7 раза вища за TLV. У приміщенні з регулятором якості повітря вміст пропілену не перевищував 180 ppm, $36 \%$ TLV. Середня концентрація $\mathrm{CO}_{2}$ становила $800 \mathrm{ppm}$, максимальна короткострокова концентрація - 1450 ppm. Система підтримувала температуру повітря в приміщенні на рівні $24 \pm 2,5^{\circ} \mathrm{C}$.

Таким чином, за умов підвищеного рівня забруднення зовнішнього повітря система забезпечила підтримання параметрів повітря приміщення в безпечних та комфортних межах відповідно до обраних установок. Слід зазначити, що запропонована система виконує додаткову сигналізаційну функцію. Під час дослідження

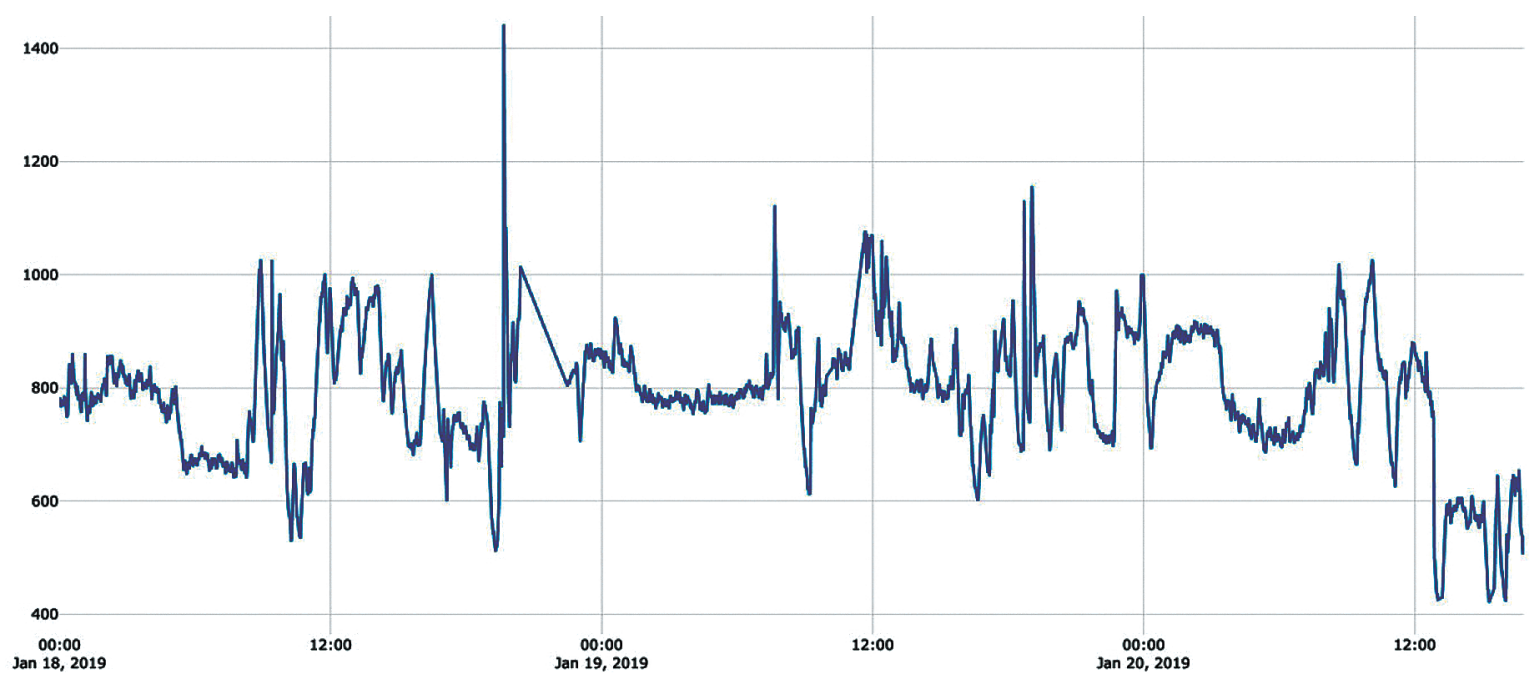

Рис. 4. Концентрація $\mathrm{CO}_{2}$ у внутрішньому повітрі під час дегазації. 


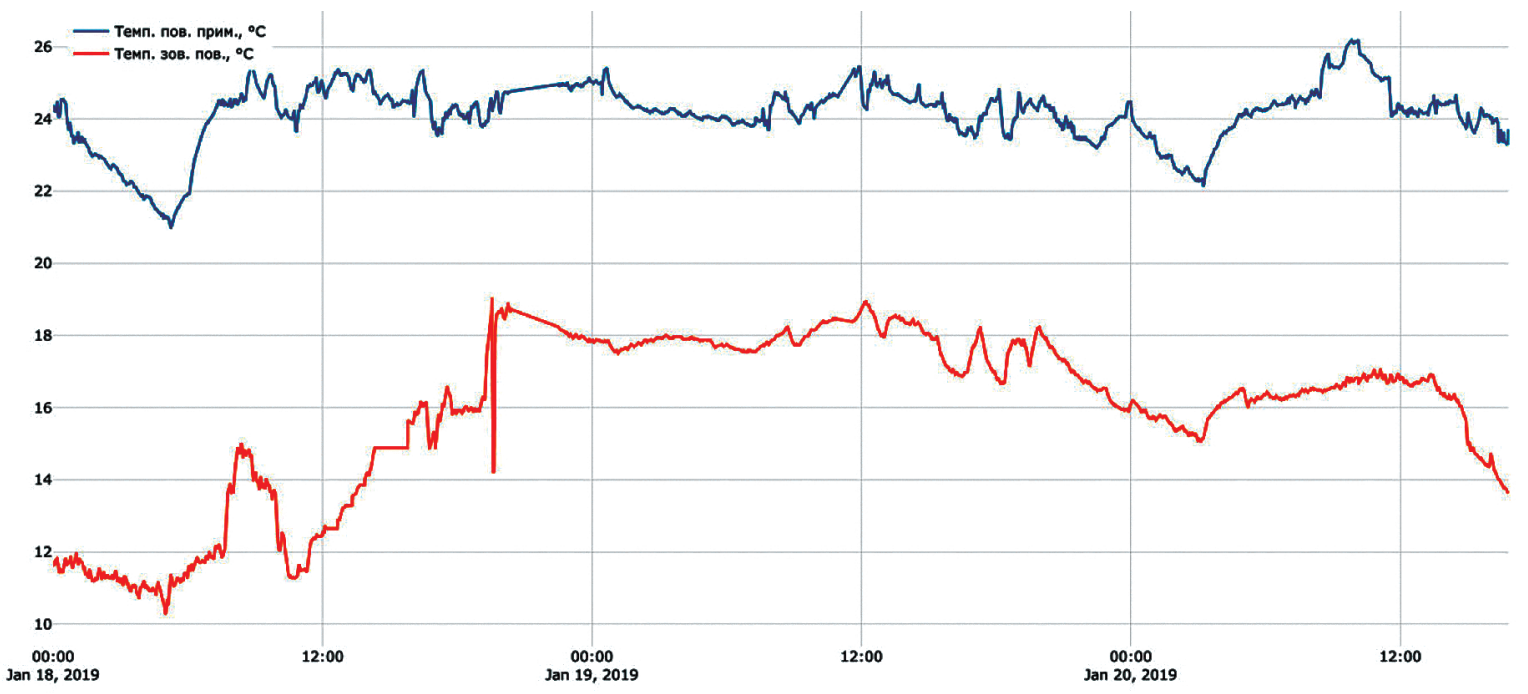

Рис. 5. Температура внутрішнього та зовнішнього повітря під час дегазації

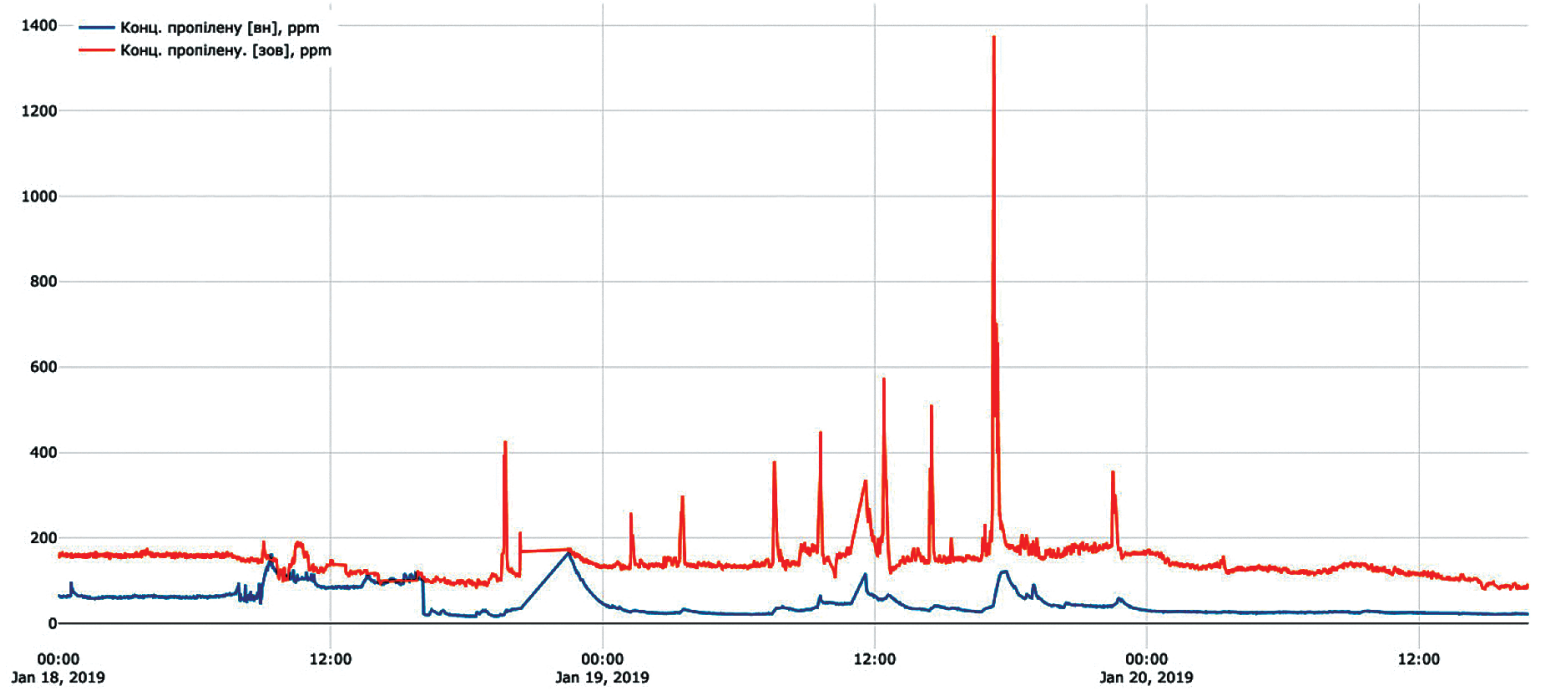

Рис. 6. Концентрації пропілену внутрішнього та зовнішнього повітря під час дегазації

нею зафіксовано витік пропілену, що стався через неякісний ремонт клапана аварійного відключення вантажного трубопроводу. Під час витоку концентрація пропілену в зовнішньому повітрі досягала 800 ppm, а в досліджуваному приміщенні не перевищувала 200 ppm. Штатна суднова система виявлення газу не сповістила про витік, оскільки налаштована на спрацювання під час досягнення концентрації вантажу в повітрі, який (згідно з вимогами IGC Code) рівний 30\% LEL (7200 pрm для пропілену).

\section{ОБГОВОРЕННЯ ОТРИМАНИХ РЕЗУЛЬТАТІВ}

Запропонована система управління якістю та комфортність повітря суднових приміщень показала високу ефективність, дозволяє тримати вміст шкідливих речовин нижче TLV (з одночасним підтриманням температури в досліджуваному приміщенні в комфортних межах).
Подальші дослідження передбачають: масштабування системи управління якістю та комфортністю на більшу кількість приміщень і внесення до ії складу приладів очищення; внесення до складу контрольованих параметрів комфортності відносної вологості повітря й енерговитрат установки кондиціювання повітря.

\section{ВИСНОВКИ}

Управління якістю повітря приміщень відіграє важливу роль у гарантуванні безпеки екіпажу, оскільки дозволяє тримати вміст шкідливих речовин у безпечних межах.

Комфортність повітря важлива для самопочуття екіпажу, його працездатності та повноцінного відпочинку.

Одночасне управління якістю та комфортністю повітря суднових приміщень потребує розробки та впровадження систем управління нового покоління, що дозволить підвищити рівень безпеки суднового середовища. 


\section{REFERENCES}

[1] Shaikh, P. H., Nor, N. B. M., Nallagownden, P., Elamvazuthi, I., \& Ibrahim, T. (2014). A review on optimized control systems for building energy and comfort management of smart sustainable buildings. Renewable and Sustainable Energy Reviews, 34, pp. 409-429.

[2] Zhang, X., Shi, W., Yan, B., Malkawi, A., Li N. (2016). Decentralized and distributed temperature control via HVAC systems in Energy Efficient Building : An approximate solution procedure. 2016 IEEE Global Conference on Signal and Information Processing (GlobalSIP).

[3] Yang, Y., Srinivasan, S., Hu, G., \& Spanos, C. J. (2021). Distributed Control of Multizone HVAC Systems Considering Indoor Air Quality. IEEE Transactions on Control Systems Technology.

[4] Lei, L., Chen, W., Xue, Y., \& Liu, W. (2019). A comprehensive evaluation method for indoor air quality of buildings based on rough sets and a wavelet neural network. Building and Environment, 162, 106296.

[5] Devarakonda, S., Sevusu, P., Liu, H., Liu, R., Iftode, L., \& Nath, B. (2013). Real-time air quality monitoring through mobile sensing in metropolitan areas. Proceedings of the 2nd ACM SIGKDD International Workshop on Urban Computing UrbComp ' 13.

[6] Zhang H., Srinivasan, R. A. (2020). Systematic Review of Air Quality Sensors, Guidelines, and Measurement Studies for Indoor Air Quality Management. Sustainability 2020, 12(21), 9045.

[7] ArduinoMega online specification. Retrieved 04.11.2021 from https://store.arduino.cc/products/arduino-mega-2560-rev3

[8] MQ-6 online specification. Retrieved 04.11.2021 from https://www.sparkfun.com/datasheets/Sensors/Biometric/MQ-6.pdf

[9] MH-Z19 online specification. Retrieved 04.11.2021 from https://www.winsen-sensor.com/d/files/PDF/Infrared Gas Sensor/ NDIR CO2 SENSOR/MH-Z19 CO2 Ver1.0.pdf

[10] MQ-135 online specification. Retrieved 04.11.2021 from https://www.winsen-sensor.com/d/files/PDF/Semiconductor Gas Sensor/MQ135

[11] BME280 online specification. Retrieved 04.11.2021 from https://cdn.sparkfun.com/assets/e/7/3/b/1/BME280_Datasheet.pdf

[12] ArduinoMega online specification. Retrieved 04.11.2021 from https://store.arduino.cc/products/arduino-nano

\section{СПИСОК ВИКОРИСТАНОЇ ЛІТЕРАТУРИ}

[1] Shaikh P.H., Nor N.B.M., Nallagownden P., Elamvazuthi I., Ibrahim T. (). A review on optimized control systems for building energy and comfort management of smart sustainable buildings. Renewable and Sustainable Energy Reviews, 34, 2014. pp. 409-429.

[2] Zhang X., Shi W., Yan B., Malkawi A., Li N. Decentralized and distributed temperature control via HVAC systems in Energy Efficient Building : An approximate solution procedure. 2016 IEEE Global Conference on Signal and Information Processing (GlobalSIP). 2016.

[3] Yang, Y., Srinivasan, S., Hu, G., \& Spanos, C. J. (2021). Distributed Control of Multizone HVAC Systems Considering Indoor Air Quality. IEEE Transactions on Control Systems Technology.

[4] Lei L., Chen W., Xue Y., Liu, W. A comprehensive evaluation method for indoor air quality of buildings based on rough sets and a wavelet neural network. Building and Environment, 162, 106296. 2019.

[5] Devarakonda S., Sevusu P., Liu H., Liu R., Iftode L., Nath B. Real-time air quality monitoring through mobile sensing in metropolitan areas. Proceedings of the 2nd ACM SIGKDD International Workshop on Urban Computing - UrbComp '13. 2013.

[6] Zhang H., Srinivasan R.A. Systematic Review of Air Quality Sensors, Guidelines, and Measurement Studies for Indoor Air Quality Management. Sustainability 2020, 12(21), 9045.

[7] ArduinoMega online specification. URL: https://store.arduino.cc/products/arduino-mega-2560-rev3

[8] MQ-6 online specification. URL: https://www.sparkfun.com/datasheets/Sensors/Biometric/MQ-6.pdf

[9] MH-Z19 online specification. URL: https://www.winsen-sensor.com/d/files/PDF/Infrared Gas Sensor/NDIR CO2 SENSOR/ MH-Z19 CO2 Ver1.0.pdf

[10] MQ-135 online specification. URL: https://www.winsen-sensor.com/d/files/PDF/Semiconductor Gas Sensor/MQ135

[11] BME280 online specification. URL: https://cdn.sparkfun.com/assets/e/7/3/b/1/BME280_Datasheet.pdf

[12] ArduinoMega online specification. URL: https://store.arduino.cc/products/arduino-nano 